\title{
Roles of the Skp2/p27 axis in the progression of chronic nephropathy
}

\author{
Sayuri Suzuki $\cdot$ Naro Ohashi $\cdot$ Masatoshi Kitagawa
}

Received: 23 September 2012 / Revised: 14 November 2012 / Accepted: 3 December 2012 / Published online: 20 December 2012 (C) The Author(s) 2012. This article is published with open access at Springerlink.com

\begin{abstract}
S-phase kinase-associated protein 2 (Skp2) is an F-box protein component of the Skp/Cullin/F-box-type E3 ubiquitin ligase that targets several cell cycle regulatory proteins for degradation through the ubiquitin-dependent pathway. Skp2-mediated degradation of p27, a cyclin-dependent kinase inhibitor, is involved in cell cycle regulation. Tubular epithelial cell proliferation is a characteristic feature of renal damage that is apparent in the early stages of nephropathy. The p27 level is associated with the progression of renal injury, and increased Skp2 expression in progressive nephropathy is implicated in decreases of p27 expression. In $\mathrm{Skp}^{-I-}$ mice, renal damage caused by unilateral ureteral obstruction (UUO) was ameliorated by p27 accumulation, mainly in tubular epithelial cells. However, the amelioration of UUO-induced renal injury in Skp2 $2^{-/-}$mice was prevented by $\mathrm{p} 27$ deficiency in Skp2 ${ }^{-1-} / \mathrm{p} 27^{-1-}$ mice. These results suggest that the Skp2-mediated reduction in $\mathrm{p} 27$ is a pathogenic activity that occurs during the progression of nephropathy. Here, we discuss the roles of the Skp2/p27 axis and/or related signaling pathways/components in the progression of chronic nephropathy.
\end{abstract}

Keywords Ubiquitin-proteasome - Ubiquitin ligase · Chronic nephropathy $\cdot$ p27 $\cdot$ Skp2

\footnotetext{
S. Suzuki $\cdot$ M. Kitagawa $(\square)$

Department of Molecular Biology, Hamamatsu University School of Medicine, 1-20-1 Handayama, Hamamatsu 431-3192, Japan e-mail: kitamasa@hama-med.ac.jp

N. Ohashi

Internal Medicine 1, Hamamatsu University School

of Medicine, Hamamatsu, Japan
}

\section{Introduction}

Cell proliferation is a fundamental biological mechanism that involves transit through the cell cycle. It is regulated by a network of proteins including cyclins, cyclin-dependent kinases (CDKs) [1], and CDK inhibitors (CKIs) [2]. The $\mathrm{CKI}$ p2 ${ }^{\text {Kipl }}(\mathrm{p} 27)$ is a negative regulator that halts progression from the G1 phase to the S phase in the cell cycle. p27 is abundantly expressed in most normal quiescent cells, whereas its level declines when cells are stimulated to proliferate in response to mitotic stimuli, allowing progression to the $S$ phase $[3,4]$. The ubiquitin-proteasome pathway for protein degradation plays an important role in regulating the abundance of cell cycle regulatory proteins $[5,6]$. Protein degradation via the ubiquitin-proteasome pathway is rapid and substrate-specific, which is consistent with its role in controlling fluctuations in the intracellular concentrations of cyclins and CKIs. S-phase kinase-associated protein 2 (Skp2) is an F-box protein component of the Skp/Cullin/F-box (SCF)-type E3 ubiquitin ligase that plays important roles in regulating the progression to the $\mathrm{S}$ phase. p27 is phosphorylated at threonine residue 187 (Thr187) by CDK2/cyclin E. The SCF/Skp2 complex interacts with phosphorylated $\mathrm{p} 27$ to promote $\mathrm{p} 27$ degradation through the ubiquitin-proteasome pathway [7, 8]. The cdc kinase subunit 1 (Cks1) is an essential cofactor for SCF/Skp2 ubiquitin ligase to ubiquitylate p27. Cks1 recognizes and binds to Thr187-phosphorylated p27 and induces rigid binding between Skp2 and p27 [9, 10]. p27 is stabilized in Skp2deficient mice [11]. Therefore, proteasomal ubiquitindependent degradation of $\mathrm{p} 27$ is specifically controlled by the SCF/Skp2/Cks1 complex.

In the kidney, cell proliferation is thought to represent a central response to renal injury culminating in end-stage renal disease caused by the progression of tubulointerstitial 
fibrosis [12]. Disruption of the balance between cell proliferation and apoptosis leads to unchecked apoptosis of damaged tubular epithelial cells resulting in progressive tubular cell loss, renal tubular atrophy, and advanced interstitial fibrosis [13].

\section{Unilateral ureteral obstruction (UUO) and anti-thymocyte serum (ATS) are models of chronic nephropathy}

UUO is a widely used model of kidney disease associated with progressive tubulointerstitial damage. This method has been used to identify many of the cellular and molecular events that occur during the progression of renal fibrosis, including events associated with cell proliferation and apoptosis [14-16]. UUO kidneys show elevated expression levels of monocyte chemoattractant protein-1 (MCP-1), vascular cell adhesion molecule-1 (VCAM-1), and intercellular adhesion molecule-1 (ICAM-1), which promote monocyte infiltration and kidney inflammation $[17,18]$. It is generally believed that renal tubule dilation occurs as a result of increased hydrostatic pressure following obstruction. However, it was also reported that decreases in renal blood flow and the glomerular filtration rate both promote macrophage invasion into the renal interstitium. The infiltrated macrophages release various cytokines, including TNF- $\alpha$ [19]. The cytokine signals and hydrostatic pressure may act collaboratively to stimulate epithelial cell proliferation, which results in an increased number of tubular epithelial cells. We previously reported that tubule dilation is correlated with the increase in number of epithelial cells and enhanced tubular epithelial cell proliferation in the obstructed kidney [20]. Taken together, these results suggest that hydrostatic pressure and tubular epithelial cell proliferation are involved

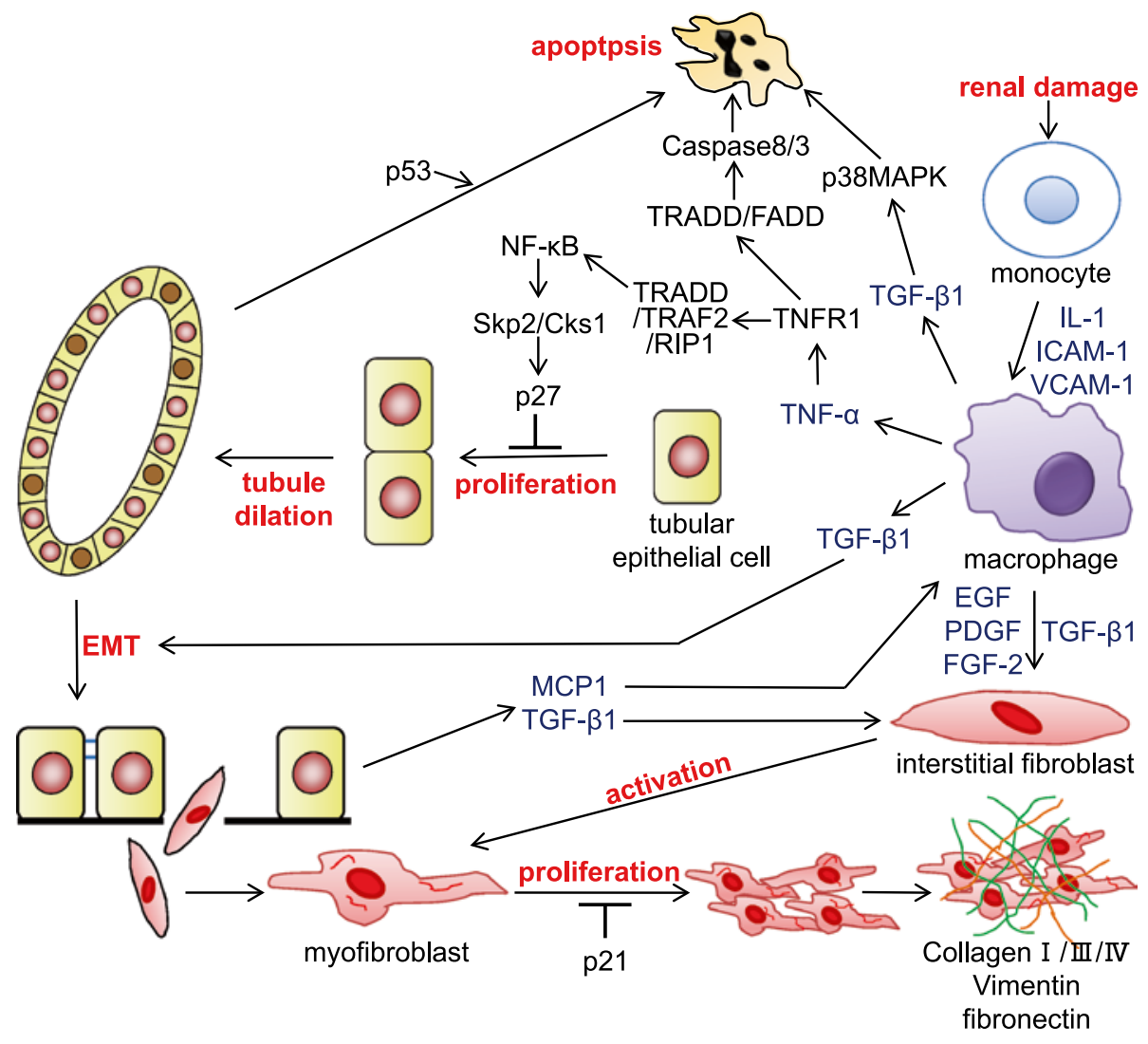

Fig. 1 The signal transduction pathways involved in the progression of chronic nephropathy. Following renal damage, infiltrated macrophages in the tubulointerstitium release cytokines such as tumor necrosis factor- $\alpha$ (TNF- $\alpha)$ and transforming growth factor- $\beta 1$ (TGF- $\beta 1$ ). TNF- $\alpha$ binds to TNF receptor 1 (TNFR1) and forms a complex with TNFR-associated death domain (TRADD), TNF associated factor 2 (TRAF2), and receptor interaction protein 1 (RIP1). This complex activates nuclear factor (NF)-кB, which induces Skp2 and Cks1. Upregulation of Skp2/Cks1 promotes p27 degradation in tubular epithelial cells, allowing proliferation of tubular epithelial cells and tubule dilation following the increase of tubular epi- thelial cell number. The tubular epithelial cells undergo epithelialmesenchymal transition (EMT) by stimulation of TGF- $\beta 1$, and the resulting fibroblasts migrate to the tubulointerstitium. Cytokines including TGF- $\beta 1$ activate fibroblasts; activated myofibroblasts produce extracellular matrix components, such as collagen, vimentin, and fibronectin. Meanwhile, TNF- $\alpha$ and TGF- $\beta 1$ induce tubular epithelial cell apoptosis. IL-1 interleukin-1, ICAM-1 intercellular adhesion molecule-1, VCAM-1 vascular cell adhesion molecule-1, $E G F$ epidermal growth factor, $P D G F$ platelet-derived growth factor, $F G F-2$ fibroblast growth factor-2, $F A D D$ Fas-associated death domain protein, $M A P K$ mitogen-activated protein kinase 
in tubule dilation. Renal tubular epithelial cell proliferation increases significantly and renal tubules start to dilate at 3 days after UUO [20,21]. The extent of tubule dilation is related to the progressive increase in tubular epithelial cell number caused by proliferation. This process ultimately results in the fracture of the tubular basement membrane of the dilated renal tubules. In damaged kidneys, tubular epithelial cells trans-differentiate into mesenchymal cells that express $\alpha$-smooth muscle actin ( $\alpha$-SMA) in response to kidney inflammation. These cells enter the tubular interstitium through the broken tubular basement membrane $[22,23]$. The trans-differentiated tubular epithelial cells further differentiate into myofibroblasts (i.e., fibroblasts expressed $\alpha$-SMA) in the interstitium. Concurrently, macrophages in the renal interstitium release several cytokines, including epidermal growth factor (EGF), platelet-derived growth factor (PDGF), and fibroblast growth factor-2 (FGF-2), which activate fibroblasts. The interstitial myofibroblasts undergo hyperproliferation because of their high cell responsiveness, resulting in irreversible progression of renal interstitial fibrosis (Fig. 1). There are many reports of establishing UUO in knockout mice and the roles of many cell cycle-related molecules in renal damage have been investigated in UUO kidneys [24].

Another experimental model of chronic progressive glomerulonephritis can be induced in rats by repeated injections of ATS. In this model, irreversible glomerulosclerosis and tubulointerstitial fibrosis are induced after the second ATS injection and are associated with a gradual decline of renal function [25-27]. Alternatively, chronic renal failure can also be studied in the 5/6 nephrectomy model $[28,29]$ and in diabetic nephropathy $[30,31]$.

\section{Signal transduction pathways involved in renal damage}

Transforming growth factor- $\beta 1$ (TGF- $\beta 1$ )/Smad pathway

TGF- $\beta 1$ is a multifunctional signaling protein that regulates cell cycle, apoptosis, differentiation, and extracellular matrix accumulation [32]. TGF- $\beta 1$ also has a significant role in the progression of renal fibrosis in clinical and experimental kidney diseases [25, 33]. Following the onset of nephropathy, TGF- $\beta 1$ is released from macrophages in the damaged renal interstitium and influences the tubular epithelial cells. The damaged tubular epithelial cells also release TGF- $\beta 1$, which exacerbates renal damage. TGF- $\beta 1$ was also reported to stimulate the epithelial-mesenchymal transition (EMT) [34-36]. Finally, tubular epithelial cells that acquire a fibroblastic phenotype via EMT migrate into the interstitium, probably through the ruptured tubular basement membrane. TGF- $\beta 1$ also promotes the differentiation of interstitial fibroblasts to myofibroblasts and their production of extracellular matrix [37, 38]. The accumulation of extracellular matrix in the tubulointerstitium and in the glomerulus is also stimulated by TGF- $\beta 1$. Conversely, TGF- $\beta 1$ promotes apoptosis of tubular epithelial cells via a p38 mitogen-activated protein kinase-dependent mechanism [39, 40]. Overall, upregulation of TGF- $\beta 1$ contributes to EMT during renal fibrosis and apoptosis, and it induces the progression of nephropathy.

In terms of the TGF- $\beta 1$ signaling pathway, Smad proteins play important roles as signal transducers downstream of TGF- $\beta 1$ receptors $[41,42]$. TGF- $\beta 1$ binds to the TGF- $\beta$ type II receptor, which recruits and phosphorylates the TGF- $\beta$ type I receptor, ALK5. In turn, ALK5 phosphorylates Smad2 and Smad3, which then bind to Smad4 [43, 44]. The resulting complexes can then enter the nucleus [45-47]. Another Smad, Smad7, has an inhibitory role in the TGF$\beta 1$ signaling pathway [48]. It was also reported that chronic progressive renal injury can be suppressed by inhibiting the TGF- $\beta /$ Smad axis using an anti-TGF- $\beta$ antibody [27]. Although TGF- $\beta 1$ signaling is also mediated by ALK1, another TGF- $\beta$ type I receptor that phosphorylates Smad1/5 [49], little is known about the roles of the ALK1/Smad1/5 pathway in renal injury. It was also suggested that TGF- $\beta$ promotes translocation of Skp2 into the nucleus, where it is degraded by the anaphase-promoting complex/cyclosome (APC/C)-Cdh1 E3 ligase. In addition, TGF- $\beta$ decreases Cks1 mRNA expression, which allows p27 to accumulate following G1 arrest [50-52]. Taken together, these findings indicate that TGF- $\beta$ is an important upstream signal that regulates the $\mathrm{Skp} 2 / \mathrm{p} 27$ axis.

Tumor necrosis factor- $\alpha(\mathrm{TNF}-\alpha) /$ nuclear factor (NF)-кB pathway

TNF- $\alpha$ is a multifunctional cytokine that induces a wide range of cellular responses, including proliferation, differentiation, and activation of apoptosis [53]. TNF- $\alpha$ is produced by activated macrophages, and it stimulates the proliferation and apoptosis of renal tubular epithelial cells and interstitial cells in renal injury [54-56]. TNF- $\alpha$ binds to two different TNF receptors (TNFR), type 1 and type 2 receptors [57, 58]. On binding of TNF- $\alpha$ to TNFR1, TNFR1 recruits TNFRassociated death domain (TRADD) as an adaptor protein thorough death domain within 2 min. In turn, TRADD serves as an assembly platform protein to arborize TNFR1 signaling between apoptosis and anti-apoptosis/proliferation. TRADD recruits Fas-associated death domain protein (FADD) to its death domain and activates the Caspase-8/-3 cascade to induce apoptosis $[59,60]$. TRADD also recruits TNF-associated factor 2 (TRAF2) and receptor interaction protein (RIP), leading to the activation of NF- $\kappa \mathrm{B}$, which has anti-apoptotic effects $[57,61]$. It has been reported that the TNFR1/TRADD/TRAF2/RIP complex is produced more 
quickly than the TRADD/FADD complex because of the antagonistic effects of the TNFR1/TRADD/FADD on apoptosis signaling pathways.

TNF- $\alpha$ can also bind to TNFR2, which recruits TRAF2 and activated NF- $\mathrm{BB}$ [62]. However, binding of TNF- $\alpha$ to TNFR2 promotes TRAF2 degradation through the ubiquitindependent proteasome pathway, resulting in the suppression of NF- $\mathrm{BB}$ activation by inhibition of TRADD/TRAF2/RIP complex formation. In addition, TNF- $\alpha$ decreases TRADD protein levels by enhancing its ubiquitin-dependent degradation in obstructive renal damage [20]. In the kidneys, it was reported that renal damage caused by cisplatin was less severe in TNFR2-deficient mice than in TNFR1-deficient mice [57]. However, renal damage in UUO mice was less severe in TNFR1-deficient mice than in TNFR2-deficient mice [63]. It was also reported that a reduction of TRADD inhibits TNFR1 signaling and that TNFR1-mediated TNF- $\alpha$ signaling may transfer to TNFR2 signaling in UUO mice [21]. Another report revealed that the two TNFRs may act collaboratively to regulate signal transduction [64, 65]. However, it has been unclear how TNFR2 regulates the TNF- $\alpha$ signaling pathway until now.

The transcription factor NF- $\kappa \mathrm{B}$, a downstream factor of $\mathrm{TNF}-\alpha$, is activated in renal damage and controls the activation of many genes related to inflammation $[66,67]$. NF- $\kappa B$ is an inductive homo- or heterodimeric transcription factor composed of the Rel family members of DNA-binding proteins, including p50/p105 (NF-кB1), p52/p100 (NF-кB2), RelA (p65), RelB, and c-Rel [68]. Activated NF-кB behaves as an important regulator of inflammation and immune responses by mediating the expression of pro-inflammatory genes, including cytokines, chemokines, growth factors, and adhesion molecules, which are implicated in the progression of renal inflammatory disease [69, 70]. The downstream targets of NF- $\mathrm{B}$ are also important regulators of cell proliferation. For example, the IкB-inducing kinase (IKK)-regulated signaling pathway accelerates cell proliferation. Furthermore, IKK- $\alpha$, an essential component of the $\mathrm{NF}-\kappa \mathrm{B}$ pathway, affects many physiologic activities in both healthy and disease states [71], including mammary epithelial cell proliferation [72]. In renal injury, NF- $\mathrm{KB}$ stimulates tubular epithelial cells and fibroblasts, and induces their proliferation and differentiation, which ultimately promote the progression of renal fibrosis [73]. It was reported that the NF- $\kappa B$ pathway regulates Skp2 expression [74, 75]. As described below, we have suggested that TNF- $\alpha$ stimulates Skp2 and Cks1 mRNA expression via the NF- $\mathrm{kB}$ pathway in chronic nephropathy [76]. Therefore, TNF- $\alpha$ is likely to participate in Skp2/Cks1-dependent degradation of p27 as a precipitating factor of chronic nephropathy.

\section{Role of the Skp2/p27 axis in the progression of renal damage}

Skp2

The SCF/Skp2 ubiquitin ligase complex targets several important regulator proteins that control the cell cycle, including p27, p21, p57, cyclin E, cyclin A, and cyclin D1 [77], by promoting their degradation via the ubiquitin proteasome-dependent pathway. In this way, Skp2 ubiquitin ligase promotes cell cycle progression to the S-phase by stimulating the degradation of negative cell cycle regulators, such as the CKI p27 [7, 8, 78] (Fig. 2). Moreover, it has been reported that Kip1 ubiqutination-promoting complex (KPC) [79] and Pirh2 [80] act as E3 ligases for p27, whereas it has not been clarified whether p27 is accumulated in their
Fig. 2 The mechanism of p27 degradation by Skp2 E3 ubiquitin ligase. SCF (Skp1/Cul1/Skp2 as F-box) ubiquitin ligase induces p27 degradation by a proteasomedependent pathway. Cks1 is an essential cofactor for $\mathrm{p} 27$ degradation by SCF/Skp2 that induces rigid binding between Skp2 and p27. Conversely, Skp2 has multiple targets and may also regulate $\mathrm{p} 21$, cyclin $\mathrm{E}$, $\mathrm{b}-\mathrm{Myb}$, and c-Myc protein levels in unilateral ureteral obstruction (UUO). However, Skp2 did not affect the regulation of cyclin A, cyclin D1, TOB1, p57, or p130 in UUO kidneys

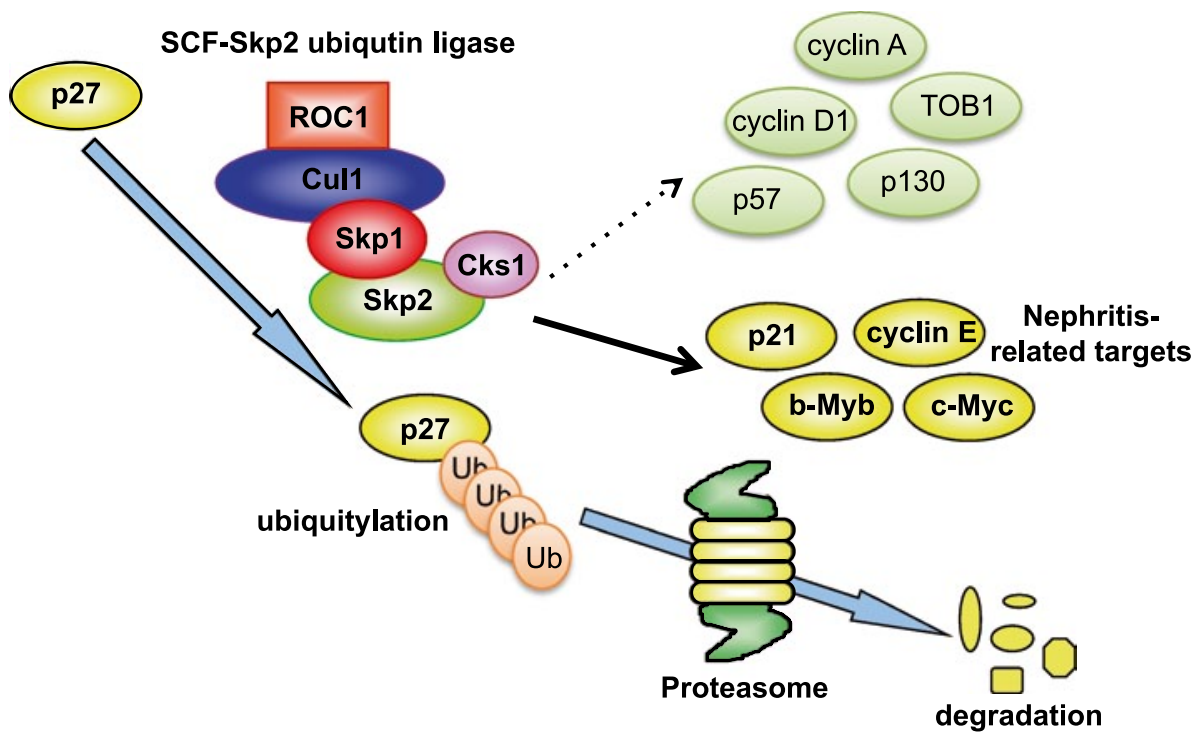


knockout mice. In human cancers, it was demonstrated that Skp2 overexpression stimulates the degradation of p27, indicating that Skp2 overexpression facilitates accelerated tumor growth and malignant potential [77]. However, the proteins that are targeted by Skp2 for degradation in specific biological processes or diseases have not been fully characterized.

We previously reported that Skp2 mRNA expression was increased in UUO kidneys in the early stages of renal damage and that the progression of tubulointerstitial fibrotic damage in UUO kidneys is attenuated in Skp2-deficient mice [20]. Furthermore, as described above, the mRNA and protein levels of Skp2 were increased in the ATS model of chronic nephropathy in rats [76]. It was reported that the NF$\mathrm{KB}$ signaling pathway regulates the Skp2 promoter in cultured cells $[74,75]$. TNF- $\alpha$ was reported to enhance mRNA expression of Skp2 in a normal rat epithelial kidney cell line (NRK) but not in control cells, which suggests that TNF- $\alpha$ facilitates the induction of Skp2 in nephropathy. In damaged kidneys, exposure to TNF- $\alpha$ significantly increased in cytoplasm of tubular epithelial cells. RelB and p52 proteins are known as NF- $\mathrm{kB}$, and they are mainly seen in the nuclei of tubular epithelial cells. Skp2 is also expressed in the nuclei of tubular epithelial cells, similar to RelB and p52. Skp2 and RelB are colocalized in renal damage [76]. These data suggest that Skp2 is induced by the TNF- $\alpha /$ RelB/p52 signaling pathway in the early stages of renal injury and facilitates ubiquitin-dependent degradation of p27 in tubular epithelial cell proliferation and in the progression of chronic nephropathy (Fig. 3).

\section{Cks1}

Cks1 is an essential cofactor for ligation of ubiquitin to p27. It recognizes Thr187-phosphorylated p27 and is essential for the rigid binding between $\mathrm{p} 27$ and Skp2 that results in Skp2mediated degradation of p27 [9, 10]. We previously reported that the mRNA and protein levels of Cks1 are increased in the early stages of renal damage [76]. Cks1 protein is mainly localized in the nuclei and to a lesser extent in the cytoplasm of tubular epithelial cells. Similar to Skp2, Cks1 colocalizes with RelB in the nuclei of tubular epithelial cells. These results suggest that Skp2 and Cks1 collaboratively promote p27 degradation via the ubiquitin proteasome pathway and induce tubular epithelial cell proliferation in the early stages of renal damage, resulting in tubular dilation in chronic nephropathy. The mRNA level of Cks1 is also significantly upregulated in TNF- $\alpha$-stimulated NRK cells. We also reported that a sequence (GGGACTTCC) in the rodent Cks1 promoter is similar to the putative NF- $\mathrm{KB}$ element (GGGACTTTCC) at nine of the ten nucleotides. Therefore, it is seems likely that the TNF- $\alpha / \mathrm{NF}-\kappa \mathrm{B}$ signaling pathway promotes the transcription of both Skp2 and Cks1 in renal injury [76].

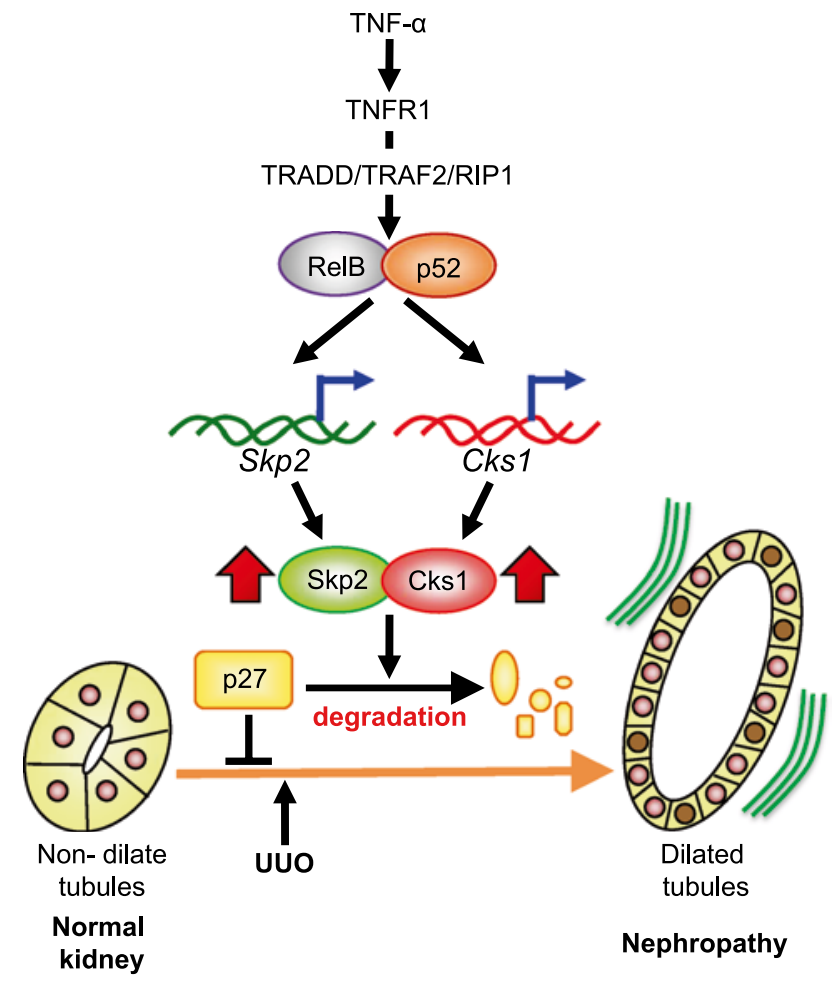

Fig. 3 Skp2/Cks1 is induced by the TNF- $\alpha$ /NF- - B signaling pathway in nephropathy. In normal kidneys, tubular epithelial cells highly express p27 in the quiescent phase of the cell cycle. Following renal damage, TNF- $\alpha$ activates RelB/p52, known as NF-кB, via TNFR1. The activated RelB/p52 complex induces the expression of both Skp2 and Cks1 in the nucleus. The induced Skp2/Cks1 degrades p27 in tubular epithelial cells in UUO kidneys, allowing tubular epithelial cell proliferation to increase [76]. Tubular dilation occurs as a result of the increase in the tubular epithelial cell number and ultimately leads to progressive nephropathy [20]

p27

The CKI p27 is an important regulator of cell proliferation that negatively regulates the behavior of CDKs in the cell cycle [81, 82]. p27 is abundantly expressed in most normal quiescent cells, but its level decreases during progression to the $\mathrm{S}$ phase in response to a proliferative/mitotic stimulus [3, 4]. In vitro studies have shown that an experimental decrease of $\mathrm{p} 27$ protein enhances the proliferative response to mitogens $[83,84]$, while forced overexpression of p27 protein inhibits cell proliferation [4]. Additionally, p27 is destabilized in many types of human cancer, which is implicated in the aggressiveness and poor prognosis of tumors [77, 85-87]. The protein level of $\mathrm{p} 27$ is controlled transcriptionally and by proteolytic degradation of p 27 protein via the ubiquitin-proteasome pathway. p27 is phosphorylated on Thr 187 by CDK [9, 10], and Thr187-phosphorylated p27 is a specific target for the SCF/Skp2/Cks1 complex to induce its ubiquitin-dependent degradation $[7,11]$. This is consistent with observations that Skp2-deficient mice and/or 
Cks1-deficient mice exhibit cellular accumulation of p27 and a small body size compared with wild-type mice $[9,10]$.

In normal kidneys, p27 is expressed in most tubular epithelial cells to maintain their quiescent status. The level of p27 protein decreases rapidly in UUO kidneys, allowing proliferation of tubular epithelial cells and tubule dilation in the early stages of nephropathy. The mRNA and protein levels of p27 are subsequently upregulated in UUO mice [88, 89]. It was reported that renal tubular epithelial cell proliferation and apoptosis are markedly increased in the obstructed kidney of p27 $7^{-I-}$ mice [90]. Additionally, the magnitude of p27 protein upregulation in obstructed kidneys is greater in $\mathrm{Skp}^{-/-}$mice than in $\mathrm{Skp}^{+/+}$mice. In the UUO kidneys of $\mathrm{Skp}^{-/-}$mice, tubular epithelial cell proliferation is inhibited by the accumulation of p27, preventing an increase in tubular epithelial cell number. Furthermore, apoptosis and tubulointerstitial fibrosis are markedly attenuated in the obstructed kidneys of Skp2 ${ }^{-/-}$mice [20]. It is well known that renal fibroblast activation and proliferation are involved in the progression of chronic kidney disease [19]. We also reported that UUO stimulates renal interstitial cell proliferation and significantly increased the number of interstitial cells in the UUO kidney [20]. The enhanced interstitial cell proliferation and the increase in number of $\alpha$-SMA-positive myofibroblasts were partially inhibited by Skp2-deficiency. p21 is the critical negative regulator of interstitial fibroblast proliferation [91]. We have shown that p21 accumulation in UUO kidneys is moderately enhanced by Skp2 deficiency [20]. In addition, the accumulation of p21 and p27 as a result of proteasome inhibition is associated with inhibition of interstitial fibroblast proliferation [92]. Therefore, p21 and p27 are negative regulators of interstitial cell proliferation while upregulated Skp2 in the UUO kidney enhances their degradation to promote interstitial fibroblast proliferation and myofibroblast formation as critical stages in the EMT. Taken together, these results suggest that Skp2 has important roles in the control of p27 and p21 in the kidney. In addition, Skp2, as induced by renal damage, promotes the proliferation of tubular epithelial cells and interstitial fibroblasts by enhancing the degradation of p27 and p21. Although further investigation is required to determine whether renal function was recovered by Skp2 deficiency, the histopathological features of Skp2 ${ }^{-/-}$UUO kidney were apparently improved compared with the WT UUO kidney. Many other studies have demonstrated increased p27 expression in other models of renal disease, including diabetic nephropathy $[30,31]$ and cisplatin-induced acute renal failure [93]. In kidney cells, mesangial cells (MC) play a key role in glomerular hypertrophy in early diabetic nephropathy [94] by secreting extracellular matrix proteins that contribute to the development of glomerulosclerosis. Increased p27 expression in the glomerulus causes proliferation arrest and hypertrophy of MCs during early diabetic nephropathy. p27 is also highly expressed in the normal quiescent rat glomeruli, but its expression decreases in proliferating MCs in the ATS model of nephropathy [95]. The p27 expression level returns to the basal level after the resolution of MC proliferation [96]. Podocyte proliferation is also markedly increased in association with glomerulonephritis in $\mathrm{p} 27^{-l-}$ mice [90]. These data indicate that p27 regulates the proliferation of various types of renal cells, and its upregulation stops excessive renal cell proliferation to protect cells and tissues from inflammatory injury.

Renal damages in Skp2 ${ }^{-/-} \mathrm{p} 27^{-1-}$ mice

Unlike the marked amelioration of renal injury associates with renal accumulation of $\mathrm{p} 27$ in tubular epithelial cells in $\mathrm{Skp} 2^{-/-}$mice, Skp2 $2^{-/-} / \mathrm{p}^{2} 7^{-/-}$double knockout mice show marked progression of tubular dilatation as a result of the enhanced tubular epithelial cell proliferation that occurs through the loss of p27 [97]. Notably, the tubular epithelial cell number in UUO kidneys is much greater in $\mathrm{Skp} 2^{-/-} \mathrm{p} 27^{-/-}$mice than in wild-type mice. Furthermore, interstitial cell proliferation in UUO kidneys is also greater in Skp2 ${ }^{-/}$p $27^{-/-}$mice than in Skp2 ${ }^{-/-}$mice. The expression levels of vimentin, $\alpha$-SMA, type I collagen, and fibronectin, components of the extracellular matrix, are significantly decreased in the UUO kidneys of Skp2 $2^{-1-}$ mice. While extracellular matrix production and macrophage infiltration are more pronounced in these mice, tubulointerstitial fibrosis progresses more in $\mathrm{Skp} 2^{-1-} \mathrm{p} 27^{-I-}$ mice compared with Skp2 ${ }^{-l-}$ mice $[20,91]$. These results suggest that Skp2 may regulate extracellular matrix synthesis by modulating p27 expression/activity in renal diseases. Taken together, these results indicate that the ameliorative effects of Skp2 deficiency following UUO are canceled by p27 deficiency in Skp2 ${ }^{-I-}$ p27 $7^{-1-}$ mice. As described above, it has been reported that proliferation is inhibited, and that the expression of p21 and p27 is increased by proteasome inhibitors in two nasal fibroblast cell lines. In these cell lines, treatment with a proteasome inhibitor suppressed fibrosis together with reduced MCP-1 production and TGF$\beta$ - and TNF- $\alpha$-induced collagen mRNA expression. Moreover, the inflammatory response in fibroblasts is inhibited by suppression of IL- $1 \beta$-/TNF- $\alpha$-induced NF- $\kappa$ B activation and IL- $1 \beta$-induced IL- $6 / 8$ production [92]. These results suggest that the accumulated p21 and p27 in fibroblasts can inhibit tissue inflammation and progressive fibrosis. In the UUO kidneys of Skp2 $2^{-/}$mice, extracellular matrix production, inflammation, and renal fibrosis may be ameliorated by p27 accumulation.

In addition to p27, Skp2 targets several other proteins that control the cell cycle, including p21, p57, cyclin E, cyclin $\mathrm{A}$, and cyclin $\mathrm{D} 1$, for degradation via the ubiquitindependent proteasome pathway. Interestingly, the protein 
levels of other Skp2 targets, including p57, p130, TOB1, cyclin A, and cyclin D1, in UUO kidneys were not significantly increased in $\mathrm{Skp}^{-1-}$ mice compared with wild-type mice. Although the levels of p21, c-Myc, b-Myb, and cyclin $\mathrm{E}$, in the UUO kidneys were slightly increased in Skp2 $2^{-/-}$ mice, the magnitudes of the increments did not reflect the accumulation of p27 [97]. These findings suggest that p27 is the main target of Skp2 and that the reduction in p27 levels has a pathogenic role in the progression of nephropathy.

\section{Other cell cycle regulators involved in nephropathy}

$$
\text { p21 }
$$

The CKI protein $\mathrm{p} 21$ has important roles in controlling cell proliferation, terminal differentiation, cellular senescence, and apoptosis [81]. p21 inhibits the cell cycle progression by binding to cyclin/CDK complexes. p21 also directly binds to proliferating cell nuclear antigen (PCNA), which inhibits the involvement of PCNA in DNA replication $[98,99]$. The protein level of $\mathrm{p} 21$ increases in Skp2 ${ }^{-/-}$mouse embryo fibroblasts during the S-phase, and its degradation is low in Skp2 ${ }^{-/-}$cells, which suggests that $\mathrm{p} 21$ is a target of Skp2 degradation in the S-phase [100]. The p21 protein level is mainly controlled by transcription, but it is also subject to ubiquitin-independent and -dependent degradation [101]. In the kidneys, p21 is upregulated in the early stages of renal injury in UUO mice [102] and ATS nephropathy [95], as well as in ischemia [103] and cisplatin-treated mice [104]. p21 levels increase dramatically following growth arrest induced by the tumor suppressor protein p53 and in the early stage of differentiation [81, 105]. p21 is also induced in p53-mediated apoptosis, as the p53-dependent pathways are involved in transactivation of the p21 gene [106]. However, p21 mRNA expression was enhanced in p53-deficient mice with nephropathy, which suggests that $\mathrm{p} 21$ transcriptional activation occurs via a 553 -independent pathway in renal damage [104]. Huge et al. also reported that the proliferation of interstitial cells, particularly myofibroblasts, was promoted in the UUO kidneys from $\mathrm{p} 21^{-/-}$mice compared with wild-type mice resulting in progression of renal failure, although there was no difference in the rate of interstitial cell apoptosis between these two strains. Tubular epithelial cell proliferation and apoptosis were also unchanged in the obstructed kidney from p21 $1^{-/-}$mice [91]. p21 plays a limited role in the proliferation of myofibroblasts in renal damage, and is not essential for the regulation of tubular epithelial cell proliferation or apoptosis following UUO. However, it was reported that p21 expression is increased in experimental diabetic nephropathy and inhibits mesangial cell proliferation [107]. Moreover, glomerular cell proliferation is significantly increased in glomerulonephritis in $\mathrm{p} 21^{-1-}$ mice [108]. Taken together, these results indicate that p21 regulates the proliferation of myofibroblasts and glomerular cells in nephropathy.

p57

The CKI protein $\mathrm{p} 57$ inhibits cell cycle progression into the S-phase. Overexpression of p57 induces G1-phase arrest $[109,110]$ and is implicated in cell cycle exit accompanying terminal differentiation [111, 112]. p57 is constitutively expressed in terminally differentiated normal mature podocytes $[113,114]$. In glomerular diseases, p57 expression is decreased in podocytes, allowing mature podocytes to proliferate and acquire an immature phenotype in response to renal injury. In the ATS model, which is associated with podocyte injury, p57 expression is markedly decreased in proliferating podocytes [115]. However, the p57 protein level remains unchanged during differentiation in cultured podocytes. These properties suggest that p57 controls the proliferation of mature podocytes in nephropathy.

p53

p53 is associated with cell proliferation, DNA repair, maintenance of DNA integrity, and apoptosis [116]. p53 regulates the induction of $\mathrm{p} 21$ and growth-arrested DNA damage protein 45 (GADD45) to control cell replication $[117,118]$. p53 mRNA expression increases rapidly after UUO. p53 induces apoptosis of severely damaged tubular cells to limit renal damage [102]. However, tubular apoptosis after UUO is also mediated by p53-independent pathways [119].

\section{Perspectives}

The number of patients with end-stage renal disease requiring renal replacement therapy is steadily increasing worldwide. However, the most effective therapies for this devastating disease are dialysis or kidney transplantation. Therefore, it is important to develop novel molecular targets for chronic kidney disease and avoid its progression to endstage renal disease. Considering the results of that reports described above, it seems likely that proteasome inhibitors have some effects on Skp2-dependent protein degradation and may offer a new therapeutic drug for nephropathy, such as kidney obstruction. It has been reported that renal fibrosis is ameliorated by proteasome inhibitors in rat obstructive nephropathy [120]. Therefore, Neubert et al. [121] suggested that proteasome inhibitors are effective for treatment of nephropathy, and Pujols et al. [92] reported that a proteasome inhibitor could reduce proliferation, collagen production, and inflammatory responses in nasal fibroblasts. 
However, proteasome inhibitors reportedly show severe side effects because they accumulate many proteins by inhibition of proteasome-mediated degradation [122]. A described above, renal damage in UUO kidneys, including interstitial fibrosis, is markedly attenuated in $\mathrm{Skp}^{-/-}$mice compared with wild-type mice. The decreased tubular epithelial cell proliferation and reduced tubule dilation may effect the inhibition of EMT $[22,34-36]$ in the UUO kidneys of Skp2 $2^{-/-}$ mice. We suggest that the progression of renal damage is stopped at an early stage by Skp2 deletion, reducing the extent of renal fibrosis in UUO kidneys of Skp2 ${ }^{-1-}$ mice. Cks1 also increases p27 degradation in the early stage of renal damage, and Skp2 and Cks1 promote p27 degradation selectively in a collaborative manner. Therefore, we think an inhibitor for SCF-Skp2/Cks1 E3 ligase will offer a specific therapeutic target for renal injury and is likely to inhibit the progression of nephropathy.

Open Access This article is distributed under the terms of the Creative Commons Attribution License which permits any use, distribution, and reproduction in any medium, provided the original author(s) and the source are credited.

\section{References}

1. Morgan DO (1995) Principles of CDK regulation. Nature 374:131-134

2. Sherr CJ, Roberts JM (1995) Inhibitors of mammalian G1 cyclin-dependent kinases. Genes Dev 9:1149-1163

3. Nourse J, Firpo E, Flanagan WM et al (1994) Interlukin-2-mediated elimination of the p27kip1 cyclin-dependent kinases inhibitor prevented by rapamycin. Nature 372:570-573

4. Polyak K, Lee MH, Erdjument-Bromage H et al (1994) Cloning of p27kip1, a cyclin-dependent kinases inhibitor and potential mediator of extracellular antimitogenic signals. Cell 78:59-66

5. Weissman AM (1997) Regulating protein degradation by ubiquitination. Immunol Today 18:189-198

6. Hershko A, Ciechanover A (1998) The ubiquitin system. Annu Rev Biochem 67:425-479

7. Carrano AC, Eytan E, Hershko A et al (1999) SKP2 is required for ubiquitin-mediated degradation of the CDK inhibitor p27. Nat Cell Biol 1:193-199

8. Tsvetkov LM, Yeh KH, Lee SJ et al (1999) p27(Kip1) ubiquitination and degradation is regulated by the $\mathrm{SCF}(\mathrm{Skp} 2)$ complex through phosphorylated Thr187 in p27. Curr Biol 9:661-664

9. Spruck C, Strohmaier H, Watson M et al (2001) A CDK-independent function of mammalian Cks1: targeting of SCF (Skp2) to the CDK inhibitor p27Kip1. Mol Cell 7:639-650

10. Ganoth D, Bornstein G, Ko TK et al (2001) The cell-cycle regulatory protein $\mathrm{Cks} 1$ is required for SCF-Skp2-mediated ubiquitinylation of p27. Nat Cell Biol 3:321-324

11. Nakayama K, Nagahama H, Minamishima YA et al (2000) Targeted disruption of Skp2 results in accumulation of cyclin $\mathrm{E}$ and p27kip1, polyploidy and centrosome overduplication. EMBO J 19(9):2069-2081

12. Couser WG, Johnson RJ (1994) Mechanisms of progressive renal disease in glomerulonephritis. Am J Kidney Dis 23:193-198

13. Gobe GC, Axelsen RA (1987) Genesis of renal tubular atrophy in experimental hydronephrosis in the rat. Role of apoptosis. Lab Invest 56:273-281
14. Walton G, Buttyan R, Garcia Montes E et al (1992) Renal growth factor expression during the early phase of experimental hydronephrosis. J Urol 148:510-514

15. Klahr S, Morrissey J (2002) Obstructive nephropathy and renal fibrosis. Am J Physiol Renal Physiol 283:F861-F875

16. Fukasawa H, Yamamoto T, Togawa A et al (2006) Ubiquitin-dependent degradation of SnoN and Ski is increased in renal fibrosis induced by obstructive injury. Kidney Int 69:1733-1740

17. Schreiner GF, Harris KP, Purkerson ML et al (1988) Immunological aspects of acute ureteral obstruction: immune cell infiltrate in the kidney. Kidney Int 34(4):487-493

18. Ricardo SD, Levinson ME, DeJoseph MR et al (1996) Expression of adhesion molecules in rat renal cortex during experimental hydronephrosis. Kidney Int 50(6):2002-2010

19. Chevalier RL, Forbes MS, Thornhill BA et al (2009) Ureteral obstruction as a model of renal interstitial fibrosis and obstructive nephropathy. Kidney Int 75:1145-1152

20. Suzuki S, Fukasawa H, Kitagawa K et al (2007) Renal damage in obstructive nephropathy is decreased in Skp2-deficient mice. Am J Pathol 171(2):473-483

21. Misaki T, Yamamoto T, Suzuki S et al (2009) Decrease in tumor necrosis factor-alpha receptor-associated death domain results from ubiquitin-dependent degradation in obstructive renal injury in rats. Am J Pathol 175(1):74-83

22. Yamashita S, Maeshima A, Nojima Y (2005) Involvement of renal progenitor tubular cells in epithelial-to-mesenchymal transition in fibrotic rat kidneys. J Am Soc Nephrol 16(7):2044-2051

23. Liu Y (2004) Epithelial to mesenchymal transition in renal fibrogenesis: pathologic significance, molecular mechanism, and therapeutic intervention. J Am Soc Nephrol 15(1):1-12

24. Fukasawa H, Fujigaki Y, Yamamato T et al (2012) Protein degradation by the ubiquitin-proteasome pathway and organ fibrosis. Curr Med Chem 19:893-900

25. Yamamoto T, Noble NA, Miller DE et al (1994) Sustained expression of TGF-beta1 underlies development of progressive kidney fibrosis. Kidney Int 45:916-927

26. Watanabe T, Yamamoto T, Ikegaya $\mathrm{N}$ et al (2002) Transforming growth factor-beta receptors in self-limited vs. chronic progressive nephropathy in rats. J Pathol 198(3):397-406

27. Fukasawa H, Yamamoto T, Suzuki H et al (2004) Treatment with anti-TGF-beta antibody ameliorates chronic progressive nephritis by inhibiting Smad/TGF-beta signaling. Kidney Int 65:63-74

28. Ng YY, Huang TP, Yang WC (1998) Tubular epithelial-myofibroblast transdifferentiation in progressive tubulointerstitial fibrosis in 5/6 nephrectomized rats. Kidney Int 54(3):864-876

29. Sinuani I, Weissgarten J, Beberashvili I et al (2009) The cyclin kinase inhibitor p57kip2 regulates TGF-beta-induced compensatory tubular hypertrophy: effect of the immunomodulator AS101. Nephrol Dial Transplant 24(8):2328-3238

30. Wolf G, Schroeder R, Thaiss F et al (1998) Glomerular expression of p27Kip1 in diabetic db/db mouse: role of hyperglycemia. Kidney Int 53(4):869-879

31. Awazu M, Omori S, Ishikura K et al (2003) The lack of cyclin kinase inhibitor $\mathrm{p} 27$ (Kip1) ameliorates progression of diabetic nephropathy. J Am Soc Nephrol 14(3):699-708

32. Border WA, Ruoslahti E (1992) Transforming growth factorbeta in disease: the dark side of tissue repair. J Clin Invest 90:1-7

33. Eddy AA (1996) Molecular insights into renal interstitial fibrosis. J Am Soc Nephrol 7:2495-2508

34. Border WA, Noble NA (1994) Transforming growth factor beta in tissue fibrosis. N Engl J Med 331:1286-1292

35. Okada H, Danoff TM, Kalluri R et al (1997) Early role of Fsp1 in epithelial-mesenchymal transformation. Am J Physiol 273:F563-F574 
36. Fan JM, Ng YY, Hill PA et al (1999) Transforming growth factor-beta regulates tubular epithelial-myofibroblast transdifferentiation in vitro. Kidney Int 56:1455-1467

37. Robert LC (2006) Obstructive nephropathy: towards biomarker discovery and gene therapy. Nat Clin Pract Nephrol 2:157-168

38. García-Sánchez O, López-Hernández FJ, López-Novoa JM (2010) An integrative view on the role of TGF-beta in the progressive tubular deletion associated with chronic kidney disease. Kidney Int 77(11):950-955

39. Yu L, Hébert MC, Zhang YE (2002) TGF-beta receptor-activated p38 MAP kinase mediates Smad-independent TGF-beta responses. EMBO J 21(14):3749-3759

40. Dai C, Yang J, Liu Y (2003) Transforming growth factor-beta1 potentiates renal tubular epithelial cell death by a mechanism independent of Smad signaling. J Biol Chem 278(14):12537-12545

41. Ohashi N, Yamamoto T, Uchida C et al (2005) Transcriptional induction of Smurf2 ubiquitin ligase by TGF- $\beta$. FEBS Lett 579:2557-2563

42. Fukasawa H, Yamamato T, Kitagawa M et al (2008) Regulation of TGF-beta signaling by Smads and its roles in tissue fibrosis. Curr Signal Trunsduct Ther 3:1-6

43. Böttinger EP, Bitzer M (2002) TGF-beta signaling in renal disease. J Am Soc Nephrol 13:2600-2610

44. Lin H, Wang D, Wu T et al (2011) Blocking core fucosylation of TGF- $\beta 1$ receptors downregulates their functions and attenuates the epithelial-mesenchymal transition of renal tubular cells. Am J Physiol Renal Physiol 300:F1017-F1025

45. Derynck R, Zhang Y, Feng XH (1998) Smads: transcriptional activators of TGF-beta responses. Cell 95(6):737-740

46. Togawa A, Yamamoto T, Suzuki H et al (2003) Ubiquitindependent degradation of Smad2 is increased in the glomeruli of rats with anti-thymocyte serum nephritis. Am J Pathol 163(4):1645-1652

47. Wang W, Koka V, Lan HY (2005) Transforming growth factor-beta and Smad signalling in kidney diseases. Nephrology 10(1):48-56

48. Fukasawa H, Yamamoto T, Togawa A et al (2004) Down-regulation of Smad7 expression by ubiquitin-dependent degradation contributes to renal fibrosis in obstructive nephropathy in mice. Proc Natl Acad Sci USA 101(23):8687-8692

49. Oh SP, Seki T, Goss KA et al (2000) Activin receptor-like kinase 1 modulates transforming growth factor-beta 1 signaling in the regulation of angiogenesis. PNAS 97:2626-2631

50. Wang W, Ungermannova D, Jin J et al (2004) Negative regulation of SCFSkp2 ubiquitin ligase by TGF-beta signaling. Oncogene 23(5):1064-1075

51. Liu W, Wu G, Li W et al (2007) Cdh1-anaphase-promoting complex targets Skp2 for destruction in transforming growth factor beta-induced growth inhibition. MCB 27(8):2967-2979

52. Hu D, Liu W, Wu G et al (2011) Nuclear translocation of Skp2 facilitates its destruction in response to TGF $\beta$ signaling. Cell Cycle 10(2):285-292

53. He KL, Ting AT (2002) A20 inhibits tumor necrosis factor (TNF) alpha-induced apoptosis by disrupting recruitment of TRADD and RIP to the TNF receptor 1 complex in Jurkat T cells. Mol Cell Biol 22:6034-6045

54. Misseri R, Meldrum DR, Dinarello CA et al (2005) TNFalpha mediates obstruction-induced renal tubular cell apoptosis and proapoptotic signaling. Am J Physiol Renal Physiol 288:F406-F411

55. Meldrum KK, Metcalfe P, Leslie JA et al (2006) TNF-alpha neutralization decreases nuclear factor-kappaB activation and apoptosis during renal obstruction. J Surg Res 13:182-188

56. Meldrum KK, Misseri R, Metcalfe P et al (2007) TNF-alpha neutralization ameliorates obstruction-induced renal fibrosis. Am J Physiol Regul Integr Comp Physiol 292:1456-1464
57. Ramesh G, Reeves WB (2003) TNFR2-mediated apoptosis and necrosis in cisplatin-induced acute renal failure. Am J Physiol Renal Physiol 285:F610-F618

58. Bharat BA (2003) Signaling pathways of the superfamily: a double-edged sword. Immunology 3:745-756

59. Gioacchino N, Liv MIA (2008) A birthday gift for TRADD. Nat Immunol 9(9):1015-1016

60. Wang D, Montgomery RB, Schmidt LJ et al (2009) Reduced tumor necrosis factor receptor-associated death domain expression is associated with prostate cancer progression. Cancer Res 69(24):9448-9456

61. Hsu H, Shu HB, Pan MG et al (1996) TRADD-TRAF2 and TRADD-FADD interactions define two distinct TNF receptor 1 signal transduction pathways. Cell 84:299-308

62. Rothe M, Sarma V, Dixit VM et al (1995) TRAF2-mediated activation of NF-kappa B by TNF receptor 2 and CD40. Science 269:1424-1427

63. Guo G, Morrissey J, McCracken R et al (1999) Role of TNFR1 and TNFR2 receptors in tubulointerstitial fibrosis of obstructive nephropathy. Am J Physiol 277:F766-F772

64. Weiss T, Grell M, Siemienski K et al (1998) TNFR80-dependent enhancement of TNFR60-induced cell death is mediated by TNFR-associated factor 2 and is specific for TNFR60. J Immunol 161(6):3136-3142

65. Mukhopadhyay A, Suttles J, Stout RD et al (2001) Genetic deletion of the tumor necrosis factor receptor p60 or p80 abrogates ligand-mediated activation of nuclear factor-kappa B and of mitogen-activated protein kinases in macrophages. J Biol Chem 276(34):31906-31912

66. Collins T (1993) Endothelial nuclear factor-kappa B and the initiation of the atherosclerotic lesion. Lab Invest 68(5):499-508

67. Baeuerle PA, Henkel T (1994) Function and activation of NFkappa B in the immune system. Annu Rev Immunol 12:141179

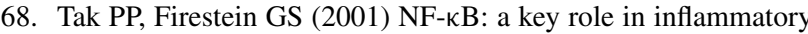
disease. J Clin Invest 107:7-11

69. Ruiz-Ortega M, Bustos C, Hernández-Presa MA (1998) Angiotensin II participates in mononuclear cell recruitment in experimental immune complex nephritis through nuclear factor-kappa $B$ activation and monocyte chemoattractant protein- 1 synthesis. J Immunol 161(1):430-439

70. Pocock J, Gómez-Guerrer C, Harendza S et al (2003) Differential activation of NF- $\kappa \mathrm{B}, \mathrm{AP}-1$, and $\mathrm{C} / \mathrm{EBP}$ in endotoxintolerant rats: mechanisms for in vivo regulation of glomerular RANTES/CCL5 expression. J Immunol 170(12):6280-6291

71. Hayden MS, Ghosh S (2004) Signaling to NF-kappaB. Genes Dev 1:2195-2224

72. Cao Y, Bonizzi G, Seagroves TN et al (2001) IKKalpha provides an essential link between RANK signaling and cyclin D1 expression during mammary gland development. Cell 107:763-775

73. Morrissey JJ, Klahr S (1997) Rapid communication. Enalapril decreases nuclear factor kappa B activation in the kidney with ureteral obstruction. Kidney Int 52(4):926-933

74. Schneider G, Saur D, Siveke JT et al (2006) IKK alpha controls p52/RelB at the skp2 gene promoter to regulate G1- to S-phase progression. EMBO J 25:3801-3812

75. Barré B, Perkins ND (2010) The Skp2 promoter integrates signaling through the NF-kappaB, p53, and Akt/GSK3beta pathways to regulate autophagy and apoptosis. Mol Cell 38:524-538

76. Suzuki S, Fukasawa H, Misaki T et al (2011) Up-regulation of Cks1 and Skp2 with TNF $\alpha / N F-\kappa B$ signaling in chronic progressive nephropathy. Genes Cells 16(11):1110-1120

77. Frescas D, Pagano M (2008) Deregulated proteolysis by the F-box proteins SKP2 and beta-TrCP: tipping the scales of cancer. Nat Rev Cancer 8:438-449 
78. Sutterlüty H, Chatelain E, Marti A et al (1999) p45SKP2 promotes p27Kip1 degradation and induces $\mathrm{S}$ phase in quiescent cells. Nat Cell Biol 1:207-214

79. Kamura T, Hara T, Matsumoto M et al (2004) Cytoplasmic ubiquitin ligase $\mathrm{KPC}$ regulates proteolysis of $\mathrm{p} 27(\mathrm{Kip} 1)$ at $\mathrm{G} 1$ phase. Nat Cell Biol 6:1229-1235

80. Hattori T, Isobe T, Abe K et al (2007) Pirh2 Promotes UbiquitinDependent Degradation of the CDK Inhibitor p2 $7^{\text {Kipl }}$. Cancer Res 67:10789-10795

81. Sherr CJ, Roberts JM (1999) CDK inhibitors: positive and negative regulators of G1-phase progression. Genes Dev 13(12):1501-1512

82. Elledge SJ, Winston J, Harper JW (1996) A question of balance: the role of cyclin-kinase inhibitors in development and tumorigenesis. Trends Cell Biol 6(10):388-392

83. Coats S, Flanagan WM, Nourse J et al (1996) Requirement of $\mathrm{p} 27^{\mathrm{kip} 1}$ for restriction point control of the fibroblast cell cycle. Science 272:877-880

84. Shankland SJ, Pippin J, Flanagan M et al (1997) Mesangial cell proliferation mediated by PDGF and bFGF is determined by levels of the cyclin kinase inhibitor p $27^{\mathrm{kip} 1}$. Kidney Int 51:1088-1099

85. Loda M, Cukor B, Tam SW et al (1997) Increased proteasomedependent degradation of the cyclin-dependent kinase inhibitor p27 in aggressive colorectal carcinomas. Nat Med 3(2):231-234

86. Esposito V, Baldi A, De Luca A et al (1997) Prognostic role of the cyclin-dependent kinase inhibitor p27 in non-small cell lung cancer. Cancer Res 57(16):3381-3385

87. Steeg PS, Abrams JS (1997) Cancer prognostics: past, present and p27. Nat Med 3(2):152-154

88. Gerth JH, Kriegsmann J, Trinh TT et al (2002) Induction of $\mathrm{p} 27^{\mathrm{KIP} 1}$ after unilateral ureteral obstruction is independent of angiotensin II. Kidney Int 61:68-79

89. Schaefer L, Macakova K, Raslik L et al (2002) Absence of decorin adversely influences tubulointerstitial fibrosis of the obstructed kidney by enhanced apoptosis and increased inflammatory reaction. Am J Pathol 160(3):1181-1191

90. Ophascharoensuk V, Fero ML, Hughes J et al (1998) The cyclindependent kinases inhibitor p2 $7^{\text {kip } 1}$ safeguards against inflammatory injury. Nat Med 4:575-580

91. Hughes J, Brown P, Shankland SJ (1999) Cyclin kinase inhibitor p21CIP1/WAF1 limits interstitial cell proliferation following ureteric obstruction. Am J Physiol 277:F948-F956

92. Pujols L, Fernández-Bertolín L, Fuentes-Prado M et al (2012) Proteasome inhibition reduces proliferation, collagen expression, and inflammatory cytokine production in nasal mucosa and polyp fibroblasts. J Pharmacol Exp Ther 343(1):184-197

93. Zhou H, Kato A, Yasuda $\mathrm{H}$ et al (2004) The induction of cell cycle regulatory and DNA repair proteins in cisplatin-induced acute renal failure. Toxicol Appl Pharmacol 200(2):111-120

94. Ibrahim HN, Hostetter TH (1997) Diabetic nephropathy. J Am Soc Nephrol 8(3):487-493

95. Chiara M, Menegatti E, Di Simone D et al (2004) Mycophenolate mofetil and roscovitine decrease cyclin expression and increase $\mathrm{p} 27$ (kip1) expression in anti Thy1 mesangial proliferative nephritis. Clin Exp Immunol 139(2):225-235

96. Shankland SJ, Hugo C, Coats SR (1996) Changes in cell-cycle protein expression during experimental mesangial proliferative glomerulonephritis. Kidney Int 50(4):1230-1239

97. Suzuki S, Fukasawa H, Misaki T et al (2012) The amelioration of renal damage in Skp2-deficient mice canceled by p27 Kip1 deficiency in Skp2 $2^{-/-}$p27 $7^{-I-}$ mice. PLoS One 7(4):e36249

98. Li R, Waga S, Hannon GJ et al (1994) Differential effects by the p21 CDK inhibitor on PCNA-dependent DNA replication and repair. Nature 371:534-537
99. Chen J, Jackson PK, Kirschner MW et al (1995) Separate domains of p21 involved in the inhibition of Cdk kinase and PCNA. Nature 374:386-388

100. Bornstein G, Bloom J, Sitry-Shevah D et al (2003) Role of the SCFSkp2 ubiquitin ligase in the degradation of p21Cip1 in S phase. J Biol Chem 278(28):25752-25757

101. Sheaff RJ, Singer JD, Swanger J et al (2000) Proteasomal turnover of p21Cip1 does not require p21Cip1 ubiquitination. Mol Cell 5(2):403-410

102. Morrissey JJ, Ishidoya S, McCrachen R et al (1996) Control of p53 and p21 (WAF1) expression during unilateral ureteral obstruction. Kidney Int Suppl 57:S84-S92

103. Megyesi J, Udvarhelyi N, Safirstein RL et al (1996) The p53-independent activation of transcription of p21 WAF1/CIP1/SDI after acute renal failure. Am J Physiol 271:F1211-F1216

104. Zhou H, Fujigaki Y, Kato A et al (2006) Inhibition of p21 modifies the response of cortical proximal tubules to cisplatin in rats. Am J Physiol Renal Physiol 291(1):F225-F235

105. Waga S, Hannon GJ, Beach D et al (1994) The p21 inhibitor of cyclin-dependent kinases controls DNA replication by interaction with PCNA. Nature 369:574-578

106. El-Deiry WS, Harper JW, O'Connor PM et al (1994) WAF1/CIP1 is induced in p53-mediated $\mathrm{G}_{1}$ arrest and apoptosis. Cancer Res 54(5):1169-1174

107. Kuan CJ, al-Douahji M, Shankland SJ (1998) The cyclin kinase inhibitor p21WAF1, CIP1 is increased in experimental diabetic nephropathy: potential role in glomerular hypertrophy. J Am Soc Nephrol 9(6):986-993

108. Kim YG, Alpers CE, Brugarolas J et al (1999) The cyclin kinase inhibitor p21CIP1/WAF1 limits glomerular epithelial cell proliferation in experimental glomerulonephritis. Kidney Int 55(6):2349-2361

109. Lee MH, Reynisdóttir I, Massagué J (1995) Cloning of p57KIP2, a cyclin-dependent kinase inhibitor with unique domain structure and tissue distribution. Genes Dev 9(6):639-649

110. Matsuoka S, Edwards MC, Bai C et al (1995) p57KIP2, a structurally distinct member of the p21CIP1 Cdk inhibitor family, is a candidate tumor suppressor gene. Genes Dev 9(6):650-662

111. Zhang P, Wong C, DePinho RA (1998) Cooperation between the Cdk inhibitors p27(KIP1) and p57(KIP2) in the control of tissue growth and development. Genes Dev 12(20):3162-3167

112. Lovicu FJ, McAvoy JW (1999) Spatial and temporal expression of p57(KIP2) during murine lens development. Mech Dev 86(1-2):165-169

113. Nagata M, Nakayama K, Terada $Y$ et al (1998) Cell cycle regulation and differentiation in the human podocyte lineage. Am J Pathol 153(5):1511-1520

114. Shankland SJ, Eitner F, Hudkins KL et al (2000) Differential expression of cyclin-dependent kinase inhibitors in human glomerular disease: role in podocyte proliferation and maturation. Kidney Int 58(2):674-683

115. Hiromura K, Haseley LA, Zhang P et al (2001) Podocyte expression of the CDK-inhibitor p57 during development and disease. Kidney Int 60(6):2235-2246

116. Hartwell LH, Kastan MB (1994) Cell cycle control and cancer. Science 266:1821-1828

117. El-Deiry WS, Tokino T, Velculescu VE et al (1993) WAF1, a potential mediator of p53 tumor suppression. Cell 75(4): $817-825$

118. Smith ML, Chen IT, Zhan Q et al (1994) Interaction of the p53-regulated protein Gadd45 with proliferating cell nuclear antigen. Science 266:1376-1380

119. Choi YJ, Mendoza L, Rha SJ et al (2001) Role of p53-dependent activation of caspases in chronic obstructive uropathy: evidence from p53 null mutant mice. J Am Soc Nephrol 12(5):983-992 
120. Tashiro K, Tamada S, Kuwabara N et al (2003) Attenuation of renal fibrosis by proteasome inhibition in rat obstructive nephropathy: possible role of nuclear factor kappaB. Int J Mol Med 12:587-592

121. Neubert K, Meister S, Moser K et al (2008) The proteasome inhibitor bortezomib depletes plasma cells and protects mice with lupus-like disease from nephritis. Nat Med 14:748-755
122. Huber JM, Tagwerker A, Heininger D et al (2009) The proteasome inhibitor bortezomib aggravates renal ischemiareperfusion injury. Am J Physiol Renal Physiol 297: F451F460 